\title{
Brainstem Tuberculoma - Presenting as Millard Gubler Syndrome
}

Sir,

A three-year-old girl presented to us with medial deviation of right eye, deviation of mouth towards left and inability to walk since one month. She had history of repeated falls on attempts to walk and history of head nodding from side to side. Development was normal till the onset of illness.

On examination, patient was well oriented, afebrile and vital parameters including blood pressure were normal. She was undernourished by Welcome Trust classification and mild pallor. BCG scar was seen. She had right side sixth and seventh nerve palsy with left hemiperesis which is clinically defined as Millard-Gubler syndrome. Rest of the neurological examination including fundus examination was normal ESR was 86 $\mathrm{mm}$ and Mantoux test was positive $(23 \mathrm{~mm} \times 27 \mathrm{~mm})$. Chest radiograph showed a mediastinal lymph node. HIV done after pre-test counselling was non-reactive. With these findings a probability of stroke or a space occupying lesion involving the brainstem was considered and neuroimaging was carried out.

MRI showed a well defined lesion which was isodense on T1W, hypodense on T2W and FLAIR, showing thick ring enhancement on post contrast scan measuring $2.3 \mathrm{~cm}$ $\times 2.6 \mathrm{~cm} \times 2.5 \mathrm{~cm}$ in right half of pons, extending partly into midbrain and right middle cerebellar peduncle suggestive of tuberculous granuloma. Mild hydrocephalus due to

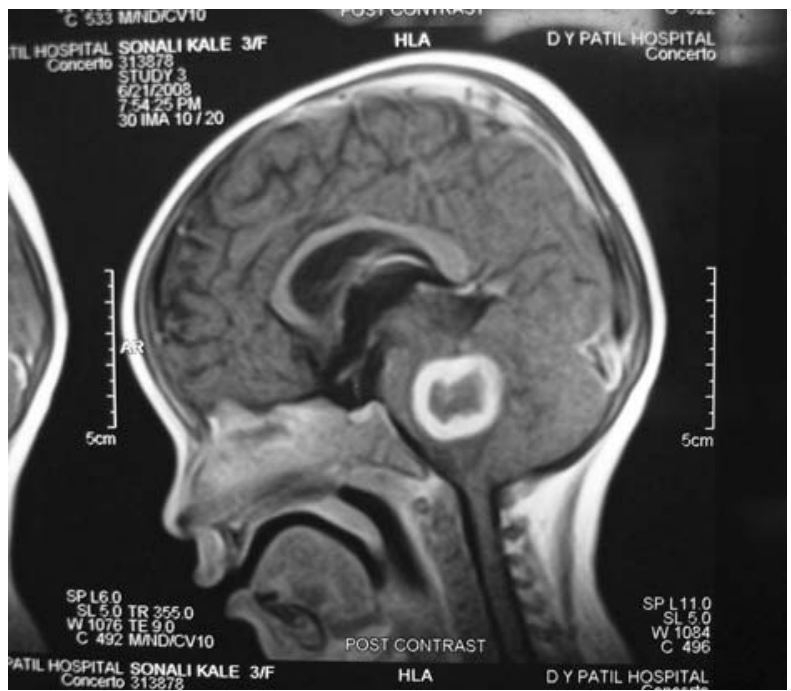

Fig. 1. Post contrast MRI showing a well defined lesion showing thick ring enhancement measuring $2.3 \mathrm{~cm} \times 2.6 \mathrm{~cm} \times 2.5 \mathrm{~cm}$ in right half of pons. perilesional edema was noted (Fig. 1).

Patient was started on anti- tubercular treatment with steroids as recommended. On follow-up after two month there is marked clinical improvement. The patient can now walk without support and the sixth nerve and facial nerve palsy are showing partial recovery.

Varieties of classical syndromes have been described in literature which involve various combinations of brainstem lesions. Millard-Gubler syndrome is one such syndrome caused by a lesion in the brainstem at the level of the facial nerve nucleus. This lesion involves the facial nerve nucleus, the abducent nerve and the corticospinal tract. Clinical features are weakness of all muscles innervated by the facial nerve and the lateral rectus on the involved side as well as weakness of the extremities on the contralateral side. ${ }^{1,2}$ It should be differentiated from Foville's syndrome, which has lateral gaze palsy in addition to findings of Millard Gubler Syndrome. This is because in Foville's syndrome, nucleus of abducent nerve which contains interneurons that project via the medial longitudinal fasciculus to the medial rectus subnucleus of the contralateral occulomotor complex is involved, producing a complete lateral gaze palsy from weakness of both, the ipsilateral lateral rectus and the contralateral medial rectus. ${ }^{3}$ Intracranial tuberculomas usually do not require surgery. They respond well to antituberculous drugs and steroids. If diagnosed early and treated promptly they can be cured leaving no sequelae. ${ }^{4}$

Mumtaz Sharif, Vaishali More and Sadhana Purandare

Department of Pediatrics, Dr. D.Y. Patil Medical College, Hospital and Research Centre, Nerul, Navi-Mumbai,

Maharashtra, India.

E-mail: morevaishali28@gmail.com [DOI-10.1007/s12098-010-0085-2]

\section{REFERENCES}

1. Udani PM. Textbook of Pediatrics, (vol 2). New Delhi; Jaypee brothers: 1998; 1236-1332.

2. Ghandhawadi B. Millard-Gubler syndrome: electrophysiologic findings. Arch Phys Med Rehabil 1988; 69: 980-982.

3. Fauci AS, Braunwald E, Isselbacher KJ, Wilson JD, Martin JB, Kasper DL et al (eds). Harrison's Principles of Internal Medicine, 16th ed. New York: McGraw Hill, Health. Professions Division; 2005.

4. Knauer-fischer S, Schaper J, Janssen H-T. Tuberculoma of pons. Pediatr Neurol 1999; 20: 57-59. 